\title{
Mechanical Characterization and Water Absorption Behaviour of Interwoven Kenaf/PET Fibre Reinforced Epoxy Hybrid Composite
}

\author{
Yakubu Dan-mallam, Tan Wei Hong, and Mohd Shukry Abdul Majid \\ Mechanical Engineering Program, School of Mechatronics Engineering, Universiti Malaysia Perlis, Pauh Putra Campus, \\ 02600 Arau, Perlis, Malaysia
}

Correspondence should be addressed to Yakubu Dan-mallam; yakubudmk4real@yahoo.com

Received 23 September 2015; Accepted 24 November 2015

Academic Editor: Atsushi Sudo

Copyright (C) 2015 Yakubu Dan-mallam et al. This is an open access article distributed under the Creative Commons Attribution License, which permits unrestricted use, distribution, and reproduction in any medium, provided the original work is properly cited.

The development of interwoven fabric for composite production is a novel approach that can be adopted to address the challenges of balanced mechanical properties and water absorption behaviour of polymer composites. In this paper, kenaf and PET (polyethylene terephthalate) fibre were selected as reinforcing materials to develop the woven fabric, and low viscosity epoxy resin was chosen as the matrix. Vacuum infusion process was adopted to produce the hybrid composite due to its superior advantages over hand lay-up technique. The weight percentage composition of the Epoxy/kenaf/PET hybrid composite was maintained at 70/15/15 and $60 / 20 / 20$, respectively. A significant increase in tensile strength and elastic modulus of approximately $73 \%$ and $53 \%$ was recorded in relation to neat epoxy. Similarly, a substantial increase in flexural, impact, and interlaminar properties was also realized in relation to neat epoxy. This enhancement in mechanical properties may be attributed to the interlocking structure of the interwoven fabric, individual properties of kenaf and PET fibres, strong interfacial bonding, and resistance of the fibres to impact loading. The water absorption of the composites was studied by prolonged exposure in distilled water, and the moisture absorption pattern was found to follow Fickian behaviour.

\section{Introduction}

In recent years, woven composite structures have dominated the auto racing, aerospace, and naval construction industry due to its exceptional mechanical performance and durability compared to unidirectional fibre composites. A two dimensional (2D) woven fabric for composite production are produced by weaving process where yarns are interlaced in two mutually orthogonal directions (warp and weft) at $0^{\circ}$ and $90^{\circ}$ in a regular pattern or weave style. The woven fabrics contain fibres that are oriented in at least two directions to provide balanced strength, stiffness and toughness required. The fabrics produced are impregnated with a thermoplastic or thermosetting resin by hand lay-up technique, compression moulding, resin transfer, or autoclave moulding. Previous studies on woven fabric composites revealed that they have better out-of-plane strength and stiffness than laminate and unidirectional composites $[1,2]$. Another major benefit of woven fabrics in composites is that when a strand is punctured or bent in a weave exposed to bearing load, the surrounding fibres withstand the stress without subsequent failure of the composite. This is unlikely to occur in unidirectional strands where the fibres can only withstand tensile, compressive, and flexural loads parallel to the loading axis. A study on mechanical performance of woven kenaf-Kevlar reinforced epoxy hybrid composite was conducted by Yahaya et al. [3]. The composites were produced by hand lay-up technique followed by compression moulding at different fibre volume fractions. The results of the investigation revealed that the mechanical properties of the composites improved in relation to neat epoxy, and the hybrid composites showed a considerable increase in mechanical properties when compared to woven kenaf fibre reinforced epoxy composites. Some researchers have investigated the mechanical properties of woven fibre reinforced polymer composites subjected to tensile and flexural loadings, and the results of the investigation 
showed a considerable increase in multiaxis properties when compared to unidirectional fibre composites $[4,5]$. Porras and Maranon investigated the mechanical performance of woven bamboo fabric reinforced polylactic acid (PLA) composite, and it was reported that woven bamboo fabric exhibited good mechanical properties under tensile, flexural, and impact loadings due to enhanced interphase bonding between the woven bamboo fibre and the biodegradable thermoplastic matrix [2].

The parameters of woven fabric composites such as fibre geometry, weaving architecture, and hybridization can be improved to increase their mechanical performance for high strength applications. Previous studies conducted on hybridization of woven fibre composites mainly focused on stacking sequence of fabric materials, arranged in different layers to offer a distinct property in each ply, with less emphasis on achieving high strength and stiffness in a single ply. This leads to the development of interwoven fabric which is made by interweaving two or more distinct yarns with diverse mechanical properties, in two mutually orthogonal directions to one another. A single woven fabric consisting of a high modulus and high strength fibre has the potential of improving stress distribution in a polymer composite. Natural fibre composites which are commonly prone to moisture absorption can be hybridized with a synthetic fibre to form an interwoven fabric, thus reducing the rate of water uptake, and increase fibre-matrix interfacial adhesion. The main benefit of using two or more distinct fibres (interwoven) to produce a woven fabric is to achieve high strength, high modulus, and considerable toughness in multiple axes, in a single ply. However, this may not be achievable in a woven fabric with single reinforcement, since the material properties are likely to be the same in both axes as reported by other researchers $[4,6,7]$.

The primary objective of this study is to investigate the mechanical properties and water absorption behaviour of interwoven kenaf/PET fibre reinforced epoxy hybrid composite. The selection of kenaf fibre was based on its good mechanical properties and availability over some locally available natural fibres. Likewise, the selection of PET fibre was based on its good mechanical properties, low cost, and hydrophobic characteristics. The manufacturing method adopted was vacuum infusion due to its superior advantages over hand lay-up technique such as lower void content, higher fibre volume fraction, and emissions-free environment and less manpower. The liquid epoxy resin chosen was EpoxAmite with a 103 slow hardener and is often mixed with the hardener according to the ratio specified in the manufacturer's guideline. The selection of this epoxy resin was due to its low viscosity; it is odourless and cures at room temperature. The weight percentage composition of epoxy resin, kenaf, and PET fibre in the composite stands at 70/15/15 and 60/20/20, respectively.

\section{Materials and Methods}

2.1. Materials. The reinforcements used in this study were continuous kenaf and PET yarn supplied in the form of yarn bundles by Innovative Pultrusion Sdn. Bhd. The diameter of kenaf yarn used in this study was approximately $1 \mathrm{~mm}$ while that of PET yarn was nearly $0.3 \mathrm{~mm}$. The kenaf yarn has a density of approximately $1.4 \mathrm{~g} / \mathrm{cm}^{3}$ while the PET yarn has a density of nearly $1.38 \mathrm{~g} / \mathrm{cm}^{3}$. The percentage elongation at failure of the kenaf and PET yarn stands at $1.6 \%$ and $24.8 \%$, respectively. The epoxy resin used was EpoxAmite 100 supplied with a 103 slow hardener by Smooth-On, Inc., USA. The resin has a mixed viscosity value of 6.5 dynes $-\mathrm{s} / \mathrm{cm}^{2}$ with a specific gravity of 1.10 and has the ability to cure at room temperature without additional heating process.

2.2. Equipment. A universal material testing machine was used in conducting tensile, flexural, and interlaminar shear tests according ASTM D638, D790, and D2344, respectively. Impact test was conducted using a $50 \mathrm{~J}$ Charpy impact testing machine according to the specification given in ASTM D6110. A digital Rockwell hardness testing machine was used to conduct hardness test according to ASTM D785 of testing polymer composites. A $200^{\circ} \mathrm{C}$ capacity oven was used during moisture and water absorption test alongside an electronic densimeter for weight, density, and volume measurements. The weaving process was carried out using a locally constructed weaving machine designed to suit the dimensions of kenaf and PET yarn along the fabric plane. The vacuum infusion machine consists of a vacuum pump, suction and delivery hose, and a glass container for resin collection.

2.3. 2D-Weaving of Kenaf/PET Fabric. This process is characterized by monodirectional shedding where two mutually perpendicular sets of yarns or strands (warp and weft) are used to produce the woven fabric. The warp yarn runs in the longitudinal direction while the weft yarn runs in the transverse direction. In this study, kenaf yarns were used as the weft while the PET yarns were used as the warp. The construction of the weaving platform was in such a way that the tension of the warp yarns depends on the tightness of the tows which is supported by the warp yarn guiders as shown in Figures 1(a) and 1(b). The process of interlacing was achieved by passing the weft yarn over and underneath the warp yarns consecutively until the desired width of the fabric is attained and, afterwards, the weft yarn created a strong edge on the fabric in the process of turning and returning back to create another row. To achieve continuity in the interlacing process, the yarns were advancing along the warp direction by the take-up operation, until the woven process was completed. It is important to note that the geometry of the fabric is influenced by fibre size, number of warp and weft yarns per unit width and length, number of warp yarns interlacing with weft yarns, and the tension in the warp and weft yarns $[8,9]$. The fabric produced from this process is called an interwoven kenaf/PET with a thickness of approximately $1.54 \mathrm{~mm}$ for the warp tow and $1.58 \mathrm{~mm}$ for the weft tow as shown in Figure 2. The size of each fabric produced was approximately $270 \mathrm{~mm}$ long, $260 \mathrm{~mm}$ wide, and $1.55 \mathrm{~mm}$ thick.

2.4. Production of the Interwoven Hybrid Composite by Vacuum Infusion. In this process, a resin pressure gradient is created by evacuating the mould to impregnate the porous interwoven hybrid fabric. The interwoven fabric was placed on 


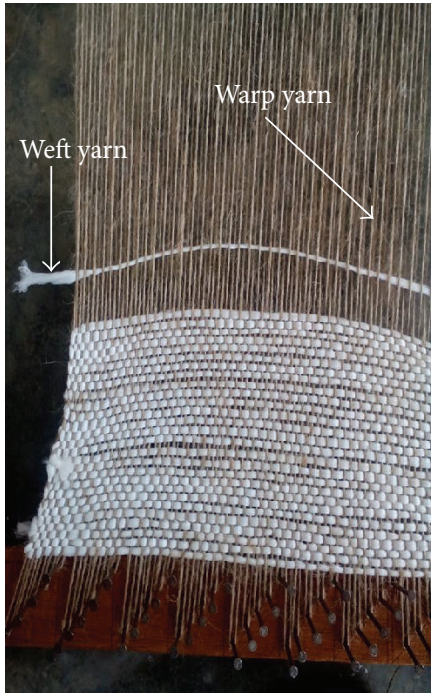

(a)



(b)

FIGURE 1: Arrangement of yarns on the weaving platform. (a) Weaving platform showing warp and weft yarn. (b) Woven fabric supported by warp yarn guiders on the platform.

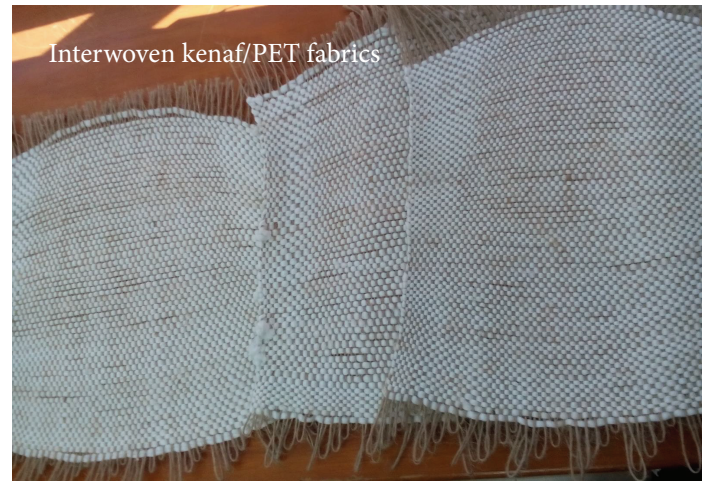

Figure 2: Finished interwoven fabrics.

a flat transparent glass in an open mould tool, and a woven plastic ply was placed on top of the woven fabric to aid easy removal of the composite after curing. The entire assembly was covered with a blue plastic mesh to control the flow of resin to all parts of the fabric as shown in Figures 3(a) and 3(b). Subsequently, the liquid epoxy resin was mixed with a slow hardener in the ratio of $3: 1$ according to the manufacturer's specification and the mixture was dispensed into a resin jar.

The vacuum pump was set to run for approximately 2 hours to create a vacuum in the open mould tool. Consequently, the resin mixture was degassed and injected into the vacuumed mould tool to fill the resin pockets created in the interwoven fabric. During this process, the liquid pressure of the epoxy resin balances off some of the compacting atmospheric pressure, hence leading to a dynamic mould cavity. The dark area of the interwoven fabric in Figure 3(a) indicates the presence of resin as it flows through the interwoven fabric while the arrow denotes the direction of resin flow.

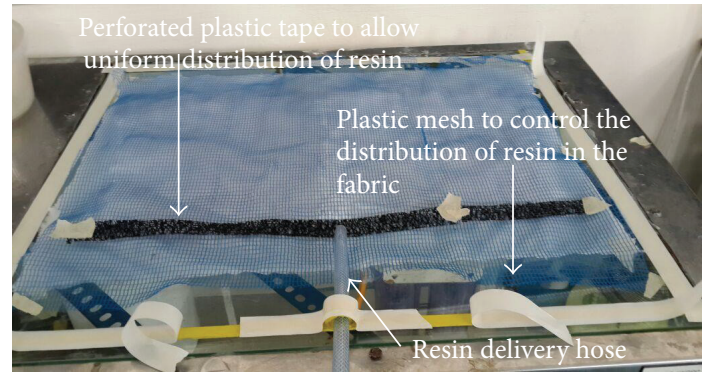

(a)

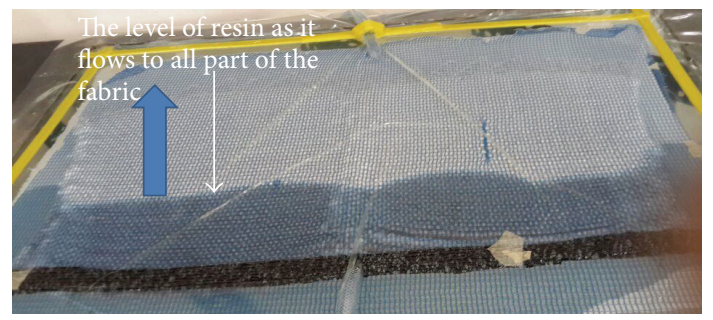

(b)

FIGURE 3: Vacuum infusion process. (a) Interwoven fabric in the mould tool before resin impregnation. (b) Interwoven fabric in the mould tool during resin impregnation.

The velocity and pressure as it flows into the fabric depend on the volume fraction and permeability of the reinforcements [10]. The injection pressure was kept at approximately 1 bar until the resin pockets in the woven fabrics are fully filled or saturated. Subsequently, the delivery lines were locked and the vacuum pressure was increased to nearly 1.3 bar to fill any remaining dry portions of the fabric. It is important to note that the resin was injected via a black perforated plastic tape positioned at the edge of the interwoven fabric to allow 


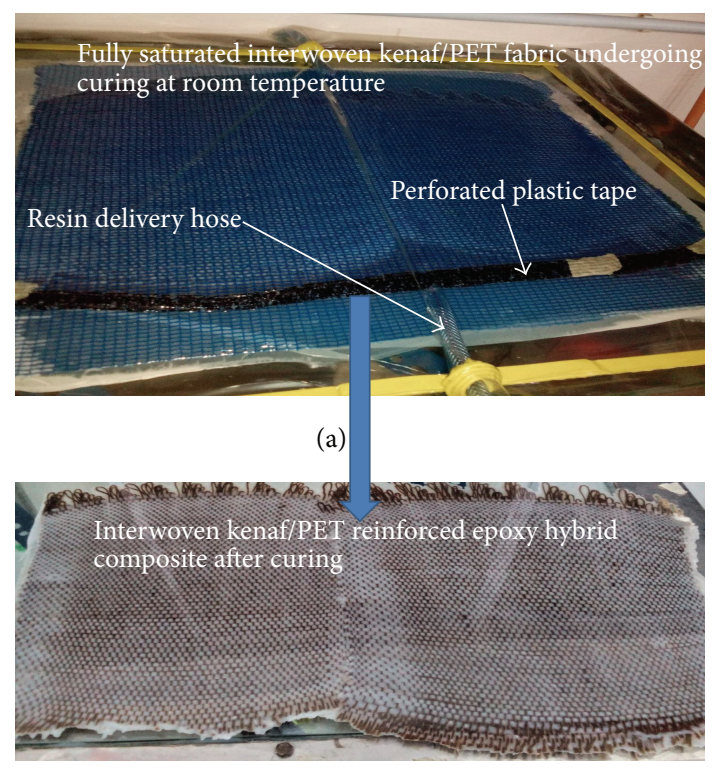

(b)

FIGURE 4: Consolidation and curing process. (a) Fully saturated interwoven fabric during consolidation and curing. (b) Cured interwoven hybrid composite.

uniform distribution of resin to all parts of the mould tool as depicted in Figure 3(b). The moulding tool was allowed to cure at room temperature $\left(24^{\circ} \mathrm{C}\right)$ for 24 hours and the finished composite was later released from the mould by detaching the plastic mesh and ply from the composite, consecutively. Figure 4(a) shows the pictorial view of the fully saturated interwoven fabric during consolidation in the mould tool, while Figure 4(b) shows the finished composite part after curing. A complete set-up of the vacuum infusion process is shown in Figure 5. It is important to note that the 70/15/15 composition was produced using one layer of the interwoven fabric, while the 60/20/20 composition was produced using two layers of the interwoven fabric.

2.5. Tensile Test. The test was conducted using a universal material testing machine according to ASTM D638 standard of testing polymeric composites. The tensile testing was considered along the warp yarn since previous studies have shown that higher tensile strength is achieved along that direction [4]. Each specimen was tested by placing it between grips of the testing machine and was tightened firmly and evenly to a degree necessary to prevent slippage and not to a point where the specimen will be scratched or crushed. A tensile load was applied at a speed of $5 \mathrm{~mm} / \mathrm{min}$ until the specimen breaks within the gauge length and, afterwards, the results of tensile strength, elastic modulus, and percentage elongation of the hybrid composites were recorded. A total of ten specimens were tested for each composition using the same specifications mentioned earlier and the results of tensile strength and elastic modulus were recorded. Figures 6(a) and 6(b) show some selected tensile specimens before and after fracture.

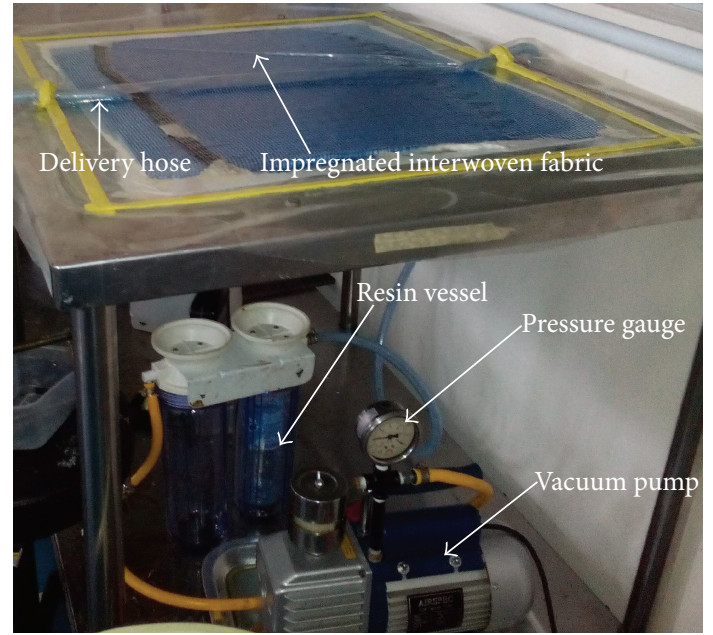

Figure 5: The complete vacuum infusion setup.

2.6. Flexural Test. A three-point bending test was conducted according to ASTM D790 of testing polymeric composites and the test was conducted in a direction perpendicular to the reinforcements. A test specimen was positioned on the surfaces of two cylindrical supports according to the span length, and the loading nose was aligned such that the axes of the cylindrical supports are parallel to each other and the loading nose is midway between the supports. The loading nose was then positioned to make contact with the specimen at $0 \mathrm{~N}$, and a load was subsequently applied to the specimen at a crosshead speed of $5 \mathrm{~mm} / \mathrm{min}$ until it breaks on the outer surface of the test specimen. The procedure was repeated for ten samples, and the results of flexural strength and modulus were recorded.

2.7. Impact Test. This test method determines the composites resistance to breakage by releasing a striking hammer to break a specimen mounted on an anvil of a standardized machine. The test standard adopted in this study was ASTM D6110, and the specimens were notched, to promote a brittle failure rather than a ductile fracture after each pendulum swing. A test specimen was placed horizontally on a jig provided on the impact testing machine and against the anvils so that it will be impacted on the face opposite the notch. The pendulum was then positioned and secured in the release mechanism and the indicator was reset to zero joules. Afterwards, the pendulum was released, the striking edge breaks the specimen, and the impact energy absorbed by the specimen was read from the indicating mechanism. Neglecting the friction loss, and winding energy, the composite impact strength was later calculated by dividing the impact energy absorbed by the thickness of the specimen.

2.8. Interlaminar Shear Test. This method was adopted to determine the short beam strength or interlaminar shear strength of the composites according to ASTM D2344 which is comparable to the testing procedure described in ASTM D790. A specimen is positioned on the surfaces of two 


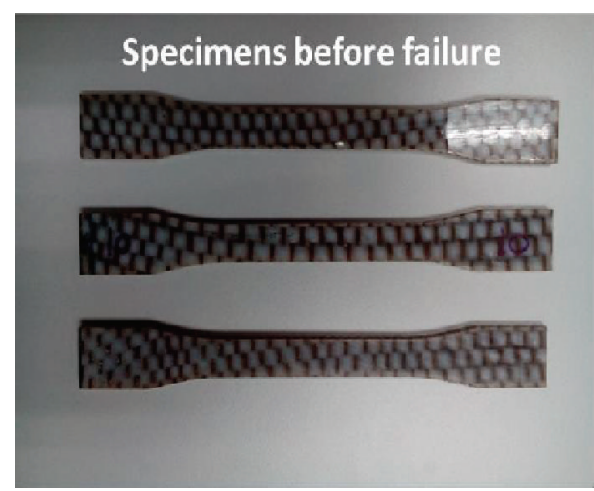

(a)

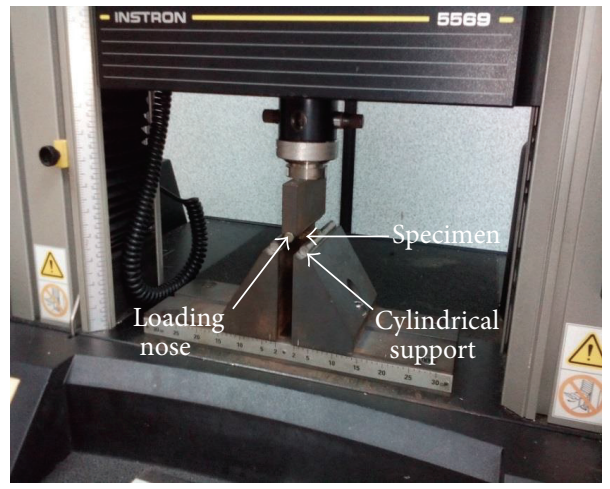

(c)

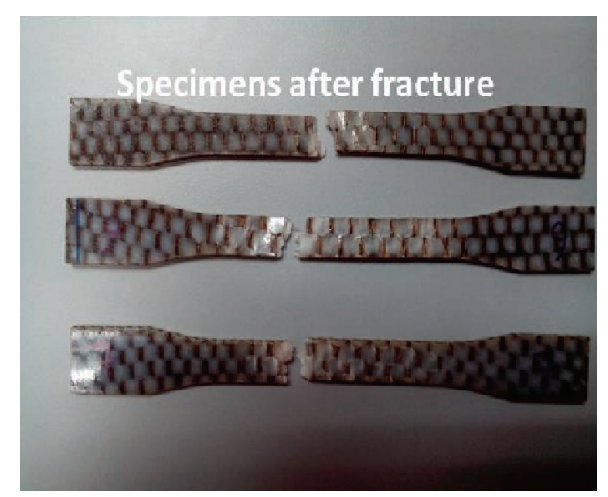

(b)

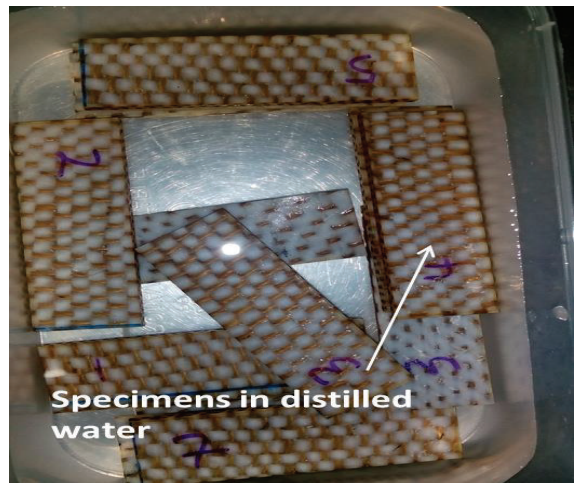

(d)

FIgURE 6: Mechanical testing and water absorption behaviour. (a) Tensile specimens before the test. (b) Tensile specimens after fracture. (c) Short beam test. (d) Fully saturated specimens in distilled water.

cylindrical supports that allow for lateral motion, and it is aligned such that the longitudinal axis of the specimen is perpendicular to the loading nose as described previously. The span length was adjusted to conform to the span lengthto-specimen thickness ratio of approximately 4.0, and the overhang length of the specimen was later adjusted to approximately $4 \mathrm{~mm}$ on both sides. Subsequently, a load was applied as shown in Figure 6(c), at a crosshead speed of $1 \mathrm{~mm} / \mathrm{min}$ until the two-piece specimen failure occurred, and the shear strength was computed using the following equation:

$$
F^{\mathrm{sbs}}=0.75 \times \frac{P_{m}}{b \times h},
$$

where $F^{\text {sbs }}$ stands for short beam strength $(\mathrm{MPa}), P_{m}$ denotes a maximum load observed during the test $(\mathrm{N}), b$ indicates measured specimen width $(\mathrm{mm})$, and $h$ stands for measured specimen thickness $(\mathrm{mm})$.

2.9. Hardness Test. The test method adopted in this study was Rockwell hardness test, and the specimens were prepared according to ASTM D785 specifications. The test measures the resistance of the composite to indentation by forcing a steel ball indenter into the surface of the composite using a specified minor load. The composite was tested by placing a specimen on the surface of the testing machine and a minor load of approximately $10 \mathrm{~kg}$ was applied to the specimen, with the gauge set to zero. A major load of $150 \mathrm{~kg}$ was applied by tripping a lever, and, after 15 seconds, the major load was removed. The hardness tester was then allowed to recover for nearly 15 seconds and the hardness number was read on a monitor with the minor load still in place. Several points on the samples were indented and the average hardness number was recorded.

2.10. Moisture Absorption. The percentage moisture content in the composites was determined using the specifications given in ASTM D5229. The weight of the composites after conditioning for seven days at $24^{\circ} \mathrm{C}$ was recorded using a balance meter and the weight after oven-drying at $100^{\circ} \mathrm{C}$ for 4 hours was subsequently measured. The percentage moisture absorption was calculated using the following equation [11]:

$$
M_{b}=\frac{M_{\mathrm{ar}}-M_{\mathrm{od}}}{M_{\mathrm{od}}} \times 100,
$$

where $M_{b}$ stands for percentage moisture content (\%), $M_{\mathrm{ar}}$ denotes as-received mass of the specimen $(\mathrm{g})$, and $M_{\mathrm{od}}$ indicates mass of oven-dried specimen ( $\mathrm{g}$ ).

2.11. Water Absorption Test. The oven-dried specimens obtained after moisture content measurements were immediately used to conduct water absorption test according to the specifications given in ASTM D570. This test method covers 
the relative water absorption rate and the determination of percentage water absorption of fully saturated specimens. The specimens were placed in a jar containing distilled water maintained at a temperature of approximately $24^{\circ} \mathrm{C}$ as shown in Figure 6(d). After every 24 hours, each specimen is removed from the distilled water, wiped with a dry cloth free of surface moisture, and weighted to the nearest $0.0001 \mathrm{~g}$. This procedure was repeated consecutively for 6 days until the composites were substantially saturated. The percentage water absorption was calculated by the difference between the weights of fully saturated specimens to the weight of dry specimens using the following equation [11]:

$$
\% W_{w}=\frac{m_{2}-m_{1}}{m_{1}} \times 100,
$$

where $W_{w}$ is the water absorption (\%) and $m_{2}$ represents the mass of fully saturated composite $(\mathrm{g})$ while $m_{1}$ denotes the mass of dry composite ( $\mathrm{g})$. The water diffusion characteristics were studied as Fickian behaviour using the following equation $[12,13]$ :

$$
\frac{M_{t}}{M_{\infty}}=4\left(\frac{D t}{\pi h^{2}}\right)^{1 / 2},
$$

where $M_{t}$ is the water content at time $t, M_{\infty}$ is the equilibrium water content, $D$ stands for diffusion coefficient, and $h$ indicates sample thickness.

2.12. Void Content and Density. The determination of void content is vital in this study since it has a detrimental effect on mechanical properties such as tensile strength, impact strength, and interlaminar shear strength. Higher void content can also lead to greater susceptibility to water penetration, environmental degradation, scatter in strength properties, and weak interfacial bonding between fibre and matrix. The void content of the composites was determined using ASTM D2734 for testing polymeric composites. In this test method, the density of epoxy resin, kenaf, and PET fibres was measured independently prior to the production of composites. Afterwards, the weight percentage of epoxy and the reinforcements were measured, and the theoretical density was calculated using the following equation:

$$
T=\frac{100}{\left(R / D+r_{k} / d_{k}+r_{p} / d_{p}\right)},
$$

wher, $T$ is the theoretical density $\left(\mathrm{g} / \mathrm{cm}^{3}\right), R$ is the weight percentage of resin in the composite (\%), $D$ indicates the density of resin $\left(\mathrm{g} / \mathrm{cm}^{3}\right), r_{k}$ is the weight percentage of kenaf in the composite (\%), $d_{k}$ denotes density of kenaf fibre $\left(\mathrm{g} / \mathrm{cm}^{3}\right), r_{p}$ is the weight percentage of PET fibre (\%), and $d_{p}$ is the density of PET fibre $\left(\mathrm{g} / \mathrm{cm}^{3}\right)$. After the theoretical density was calculated, the experimental or measured density of the composite was determined using a densimeter, according to the specifications and guidelines given in ASTM D792. Subsequently, the void content of the composite was calculated using the following equation:

$$
V=100 \frac{\left(T_{d}-M_{d}\right)}{T_{d}},
$$

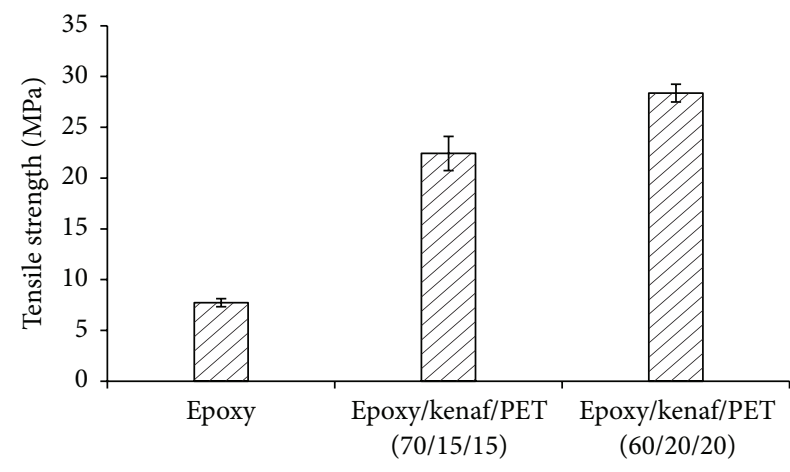

FIgURE 7: The results of tensile strength.

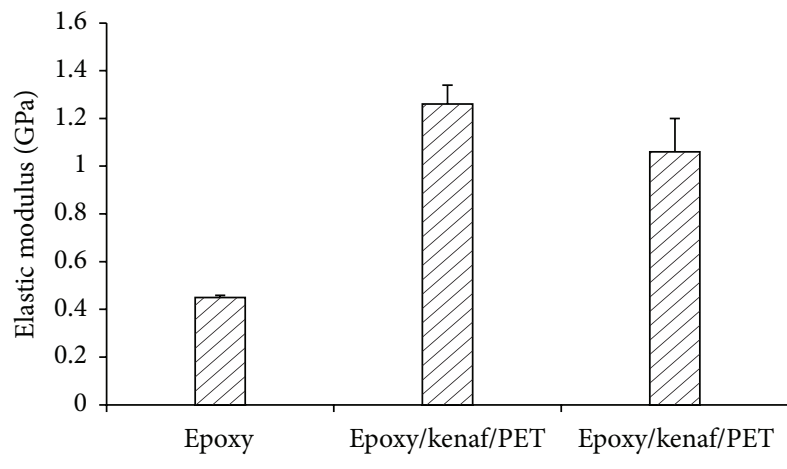

$(70 / 15 / 15)$

$(60 / 20 / 20)$

FIGURE 8: The results of elastic modulus.

where $V$ is the void content of the composite (\%), $T_{d}$ is the theoretical density, and $M_{d}$ is the measured density of the composite $\left(\mathrm{g} / \mathrm{cm}^{3}\right)$.

\section{Results and Discussion}

3.1. Tensile Properties. The results of tensile strength and elastic modulus of the interwoven hybrid composites with respect to neat epoxy are presented in Figures 7 and 8 . The tensile strength of the interwoven Epoxy/kenaf/PET (70/15/15) composite has significantly increased by approximately $65 \%$ from 7.74 to $22.43 \mathrm{MPa}$, in relation to neat epoxy. Similarly, the results of Epoxy/kenaf/PET (60/20/20) composition show an increase in tensile strength by nearly $73 \%$ with respect to neat epoxy. The percentage increase in tensile strength is much higher compared to those obtained by Yahaya et al. and Dan-mallam et al. $[3,4]$ due to better interfacial adhesion achieved during vacuum infusion process. In addition, this considerable increase in tensile strength is most probably due to the mechanical interlocking between kenaf and PET fibre in the interwoven hybrid fabric. During the tensile test, failure of the composite was characterized by progressive breakage of the fibres parallel to the loading axis. It was observed that the failure of kenaf and PET strands in the matrix originated from the centre of the gauge length and propagates widthwise along the loading direction. This phenomenon demonstrates why the failure of woven fibre composites is mostly by fibre 


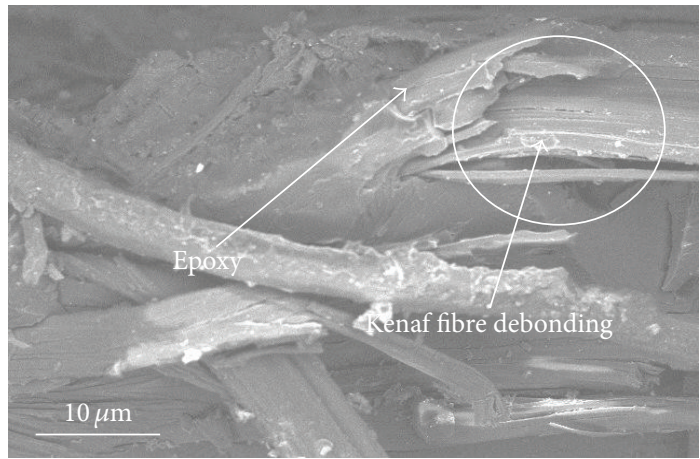

(a)

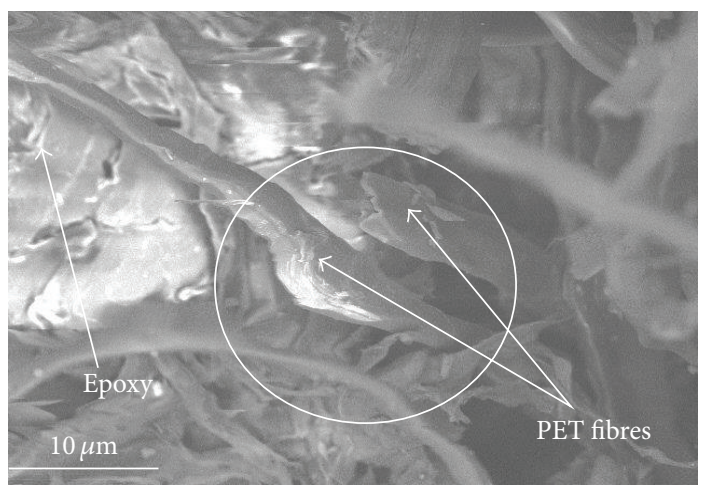

(c)

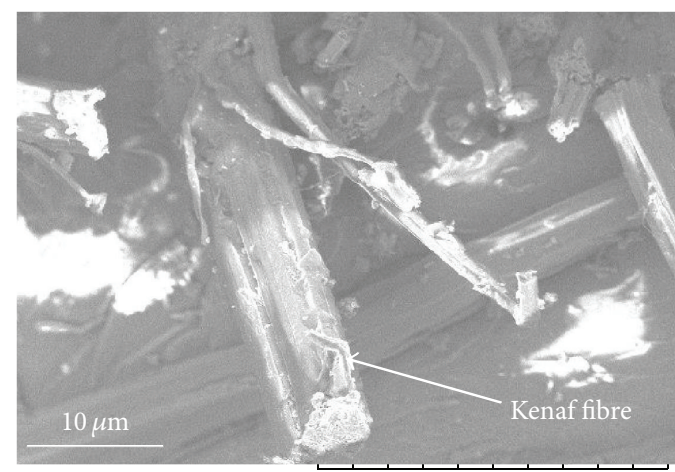

(b)

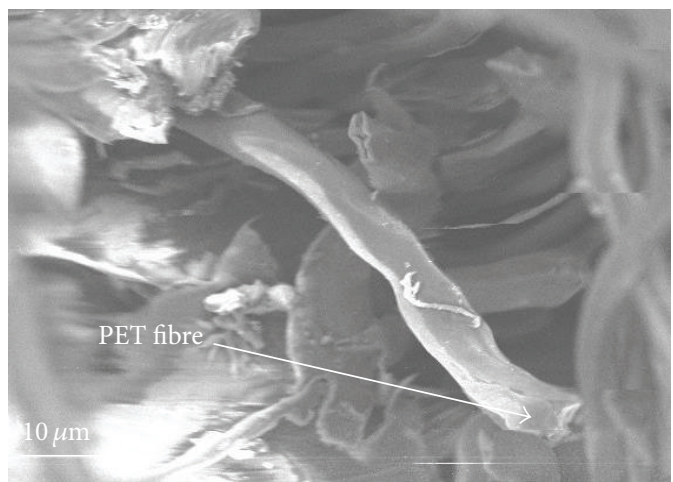

(d)

FIGURE 9: Kenaf and PET fibre morphology: (a) kenaf fibre bonding with epoxy matrix; (b) kenaf fibre morphology; (c) PET fibre bonding with epoxy; (d) PET fibre morphology.

breakage, since fibre pullout cannot be achieved by the tight network structure of the interwoven fabric.

It can be said that the strong interfacial bonding between the fibres and the matrix also influenced the substantial increase in tensile strength, due to adequate penetration of the resin as demonstrated by the SEM micrograph shown in Figures 9(a) and 9(b). Interestingly, the composite morphology illustrated by the SEM micrograph in Figures 9(c) and 9(d) shows no indication of fibre pullout and fibre debonding, thus signifying strong bond between the fibres and the matrix. The SEM micrograph also revealed that the fibre bundles are attached to the matrix, which indicates that the lower viscosity epoxy resin penetrates the interwoven fabric. Previous studies have shown that natural fibres are inherently incompatible with nonpolar epoxy resin during impregnation; however, the porosity of the reinforcements has increased the permeability of the interwoven fabric resulting in high resin uptake during injection in the mould tool [14, 15]. This progression has tremendously improved the wetting of the fibres by the resin and subsequently increased the fibre's resistance to deformation from their original cross-sectional area.

Similarly, the elastic modulus of the $70 / 15 / 15$ composition significantly increased by approximately $65 \%$ from 0.45 to 1.26 GPa in relation to neat epoxy as depicted in Figure 8. The considerable increase in elastic modulus may be attributed to the incorporation of high modulus kenaf fibre in the composite and the structure of the interwoven fabric. It can be said that the enhancement in modulus is linked to the stretching behaviour of individual reinforcement in the matrix, since the kenaf and PET strands can independently stretch and break as they approach their breaking stress [16, 17]. However, the modulus of elasticity of the $60 / 20 / 20$ composition dropped below that of 70/15/15 configuration, representing an increase in material ductility as reported by another researcher [2]. Therefore, it can be said that increase in ductility accounted for an increase in percentage elongation or tensile strain as depicted in Figure 10. The decrease in elastic modulus may also be attributed to an increase in crimp or yarn undulation during injection in the mould tool. This is expected, since some of the strands wanted to strengthen out through flexural deformation rather than carry the load entirely in tension [18, 19]. The strands that bent with different angles during consolidation in the mould tool may be subjected to higher loading in tension and can result in premature failure, thus leading to lower elastic modulus. Though it is difficult to weave a fabric without crimp, but it can be minimized by changing the weaving architecture or altering the weaving parameters such as tow size, number of warp and weft yarns, tension in the warp and weft yarn, and tightness of the tows [20]. 


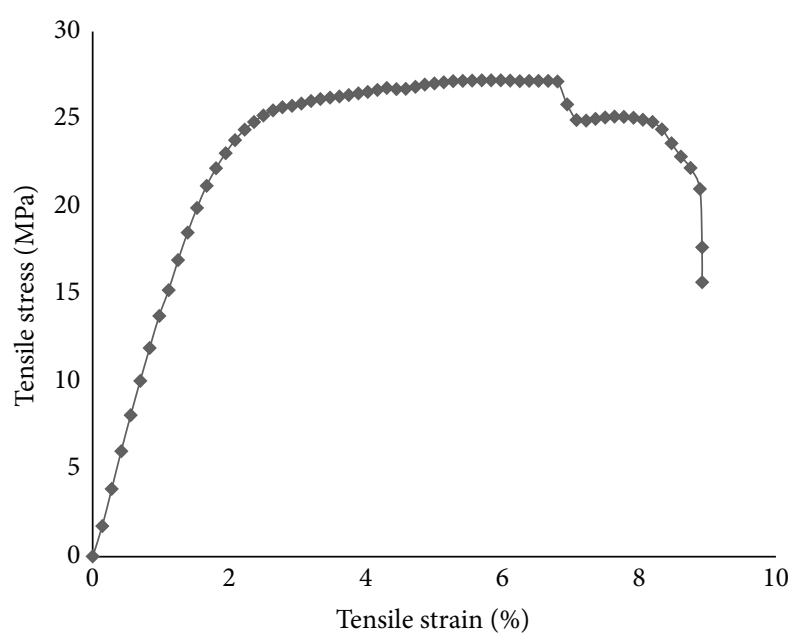

FIGURE 10: Stress-strain graph of Epoxy/kenaf/PET (60/20/20) hybrid composite.

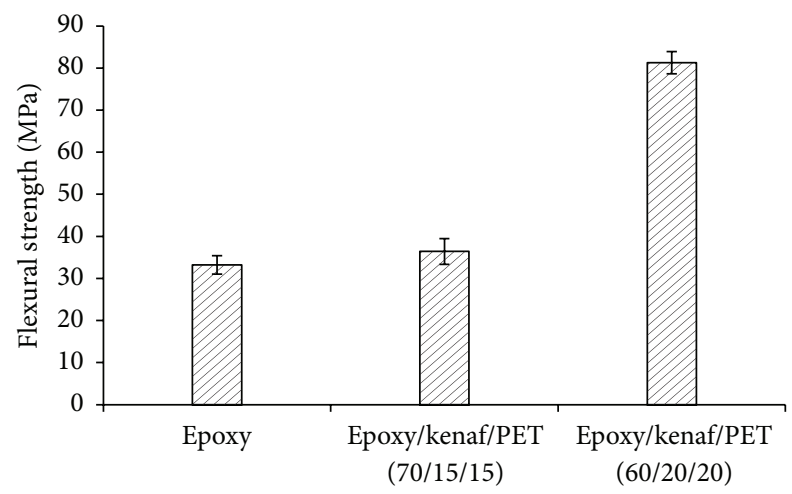

FIGURE 11: The results of flexural strength.

3.2. Flexural Properties. The flexural strength of the hybrid composites is the combination of tensile and compressive stress and varies directly with interlaminar shear strength, while the flexural modulus is a measure of the composites resistance to deformation due to deflection [21]. Figures 11 and 12 present the results of flexural strength and modulus of the hybrid composites in relation to neat epoxy. The results indicate that the 60/20/20 composition recorded the highest flexural strength of approximately 81.28 $\mathrm{MPa}$ when compared to the $70 / 15 / 15$ configuration. This enhancement in flexural strength may be attributed to the ability of the interwoven fabric to withstand bending forces during the three-point bending tests. Failure of the composite was characterized by fibre breakage and matrix cracking, which initiated from the tension side of the specimen, with fracture occurring in the middle of the beam $[22,23]$. Once the compression failure occurs, the flexural stress in the composite is reduced as the fibre breakage and matrix cracking continues to propagate along the fibre-matrix interphase.

This considerable increase in flexural strength may also be attributed to the interlocking structure of the fibres in the matrix, individual reinforcement properties, and fibrematrix interfacial adhesion. During loading, the warp strands

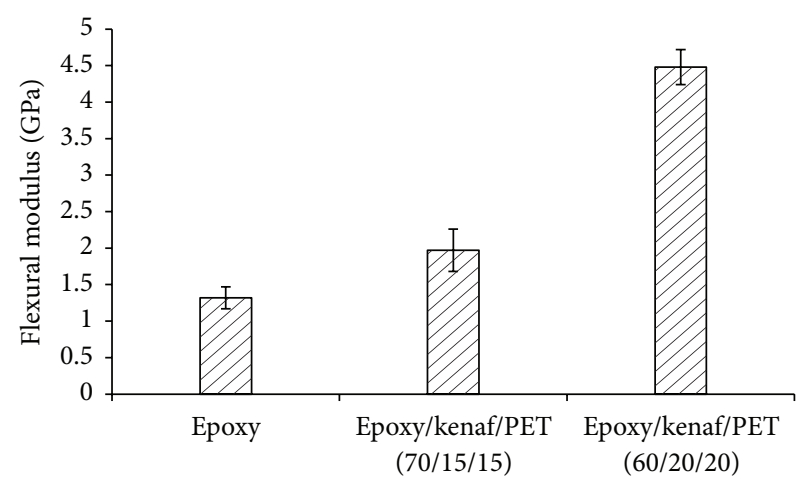

FIGURE 12: The results of flexural modulus.

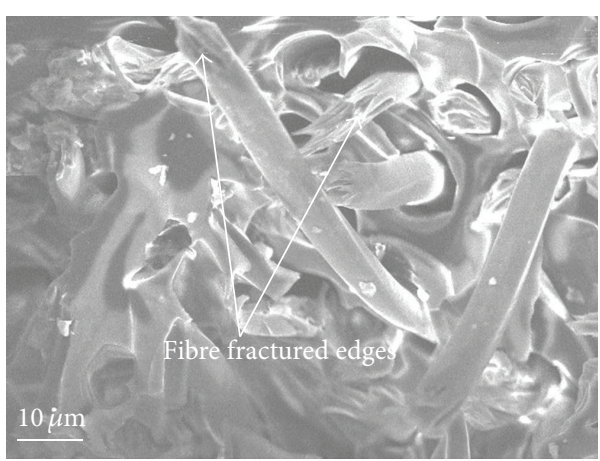

FIGURE 13: SEM micrograph shows fibre stretching after three-point bending test.

stretched out and created stresses in the weft strands that initiated crack in the matrix. The crack continued to propagate along the transverse direction, causing fractures to occur as illustrated by the SEM micrograph in Figure 13. However, the marginal increase in flexural strength of the 70/15/15 composition may be related to less number of warp and weft yarns, low tension in the warp and weft yarns, and the tightness of the tows since the stress is being transferred through the thickness of the composite.

From Figure 12, it can be observed that the flexural modulus of the 70/15/15 composition significantly increased by nearly $33 \%$ from 1.32 to $1.97 \mathrm{GPa}$, in relation to neat epoxy. Similarly, the $60 / 20 / 20$ configuration shows a considerable increase in flexural modulus, by approximately $71 \%$ from 1.32 to $4.48 \mathrm{GPa}$ with respect to neat epoxy. This substantial increase in flexural modulus may be attributed to higher initial modulus of kenaf and PET fibre and the orientation of the warp and weft yarn in the hybrid composite. A similar conclusion on the influence of fibre orientation was made by another researcher [24]. In addition, a short delamination was observed in the 60/20/20 composition after the maximum stress was attained during deformation. A possible explanation is that a strong bond between the interwoven fabric and the matrix was responsible for the short delamination, hence resulting in high flexural properties. The delamination continued to propagate along the weft direction, resulting in matrix cracking followed by kenaf fibre breakage as shown in Figure 14. A similar observation related to delamination 


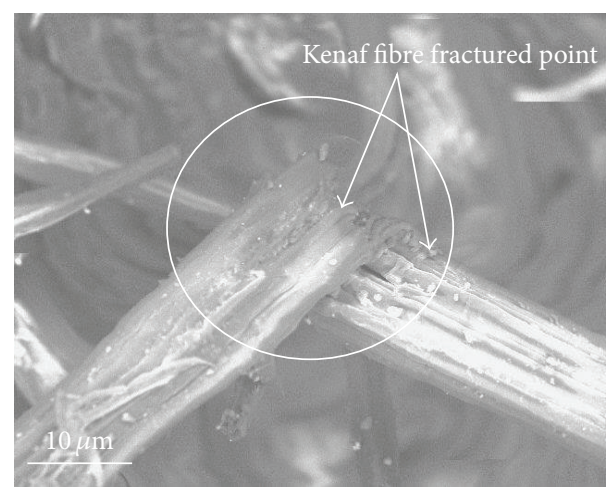

FIGURE 14: SEM micrograph shows fibre fracture after three-point bending test.

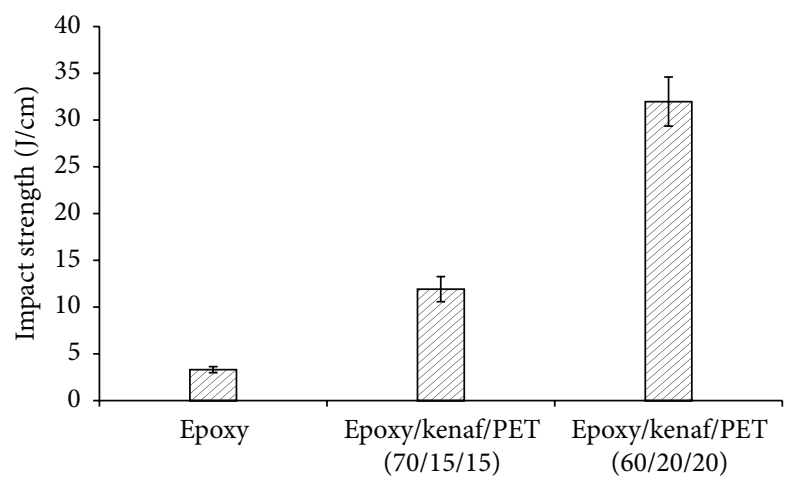

FIGURE 15: The results of impact strength.

crack and fibre-matrix debonding was reported by Soliman et al. [25] and recently by Dai et al. [1].

3.3. Impact Strength. Figure 15 presents the results of impact strength of the interwoven hybrid composites in relation to neat epoxy. An improvement of approximately $72 \%$ was achieved when the epoxy resin was reinforced with interwoven kenaf/PET fabric at 70/15/15 composition. A possible explanation is that the fracture propagation energy of the hybrid composite is higher than its fracture initiation energy. This considerable increase may be attributed to the incorporation of the interwoven kenaf and PET fabric whose initial energy absorption properties, interlocking structure, and orientation contributed to this enhancement in impact strength. The substantial increase in impact resistance may also be associated with energy losses due to vibration, fracture propagation, and friction between the striking nose and indentation.

The SEM micrograph in Figure 16 shows the surface of the interwoven hybrid composite after fracture. The smooth surfaces observed on the composite consist of fewer cavities, small perforations, and stretched fibres, which indicates a ductile fracture with little sign of fibre pullout and matrix cracking. Similar findings were reported by Fu et al. [26] and recently by Rahmanian et al. [27]. The enhancement in

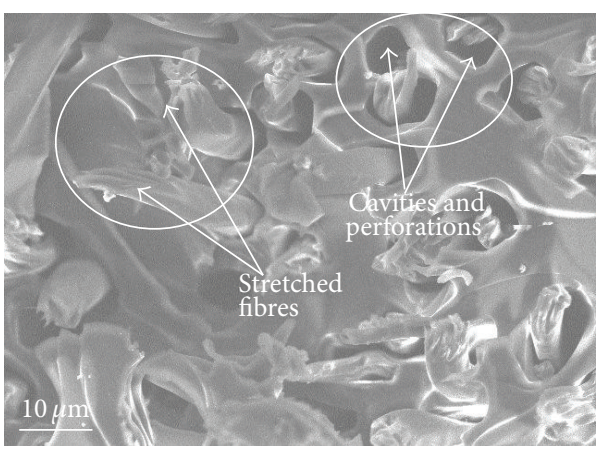

FIGURE 16: SEM micrograph shows the fractured surface of the interwoven hybrid composite after impact test.

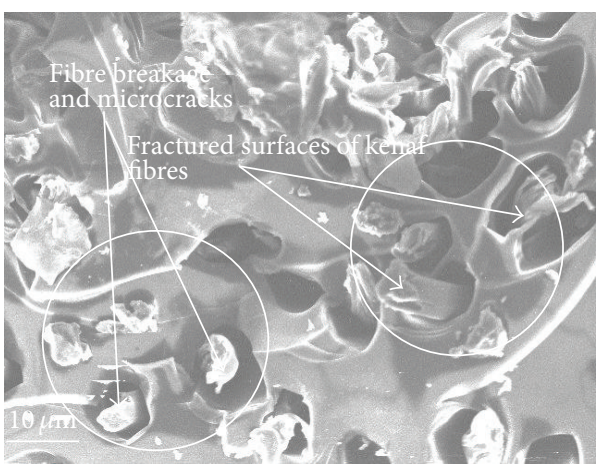

FIGURE 17: SEM micrograph shows microcracks and fibre breakage.

ductility may be attributed to interlaminar fracture toughness, damping characteristics, and bending strength of the individual slender fibre $[28,29]$. It is obvious to say that these properties hinge on the interfacial adhesion between the fibres and the matrix and mechanics of load transfer from the matrix to the interlocking fibres. A more encouraging result was achieved in the 60/20/20 composition where the impact strength increased by nearly $90 \%$ from $3.3 \mathrm{~J} / \mathrm{cm}$ to $31.9 \mathrm{~J} / \mathrm{cm}$, in relation to neat epoxy. The SEM micrograph in Figure 17 shows deformation and failure mechanisms that resulted in toughness enhancement in the interwoven hybrid composite. The fractured edges of kenaf fibre on the surface of the composites indicate that kenaf fibre has less damage resistance capability compared to PET fibre in the interwoven fabric structure; hence the PET fibre contributed more in raising the hybrid composites impact resistance.

3.4. Interlaminar Shear Strength. The results of interlaminar shear strength for 70/15/15 and 60/20/20 compositions are summarized in Table 1. It can be observed that the interlaminar shear strength of the 60/20/20 composition is higher by approximately $58 \%$ compared to the $70 / 15 / 15$ composition. This enhancement in interlaminar shear strength is most probably due to less transverse and in-plane compressive stresses that are required to initiate failure in the composite. The failure mode observed during loading was midplane interlaminar failure, with a progressive delamination widthwise along the fibre direction. It was observed that a parabolic 
TABLE 1: Results of interlaminar shear strength and Rockwell hardness number.

\begin{tabular}{lcccc}
\hline Material composition & $\begin{array}{c}\text { Average } \\
\text { maximum force } \\
(\mathrm{N})\end{array}$ & $\begin{array}{c}\text { Average } \\
\text { width } \\
(\mathrm{mm})\end{array}$ & $\begin{array}{c}\text { Average } \\
\text { thickness } \\
(\mathrm{mm})\end{array}$ & $\begin{array}{c}\text { Interlaminar shear } \\
\text { strength (ILSS) } \\
(\mathrm{MPa})\end{array}$ \\
$\begin{array}{l}\text { Interwoven epoxy/kenaf/PET } \\
(70 / 15 / 15)\end{array}$ & 47.08 & 9.53 & 2.00 & $\begin{array}{c}\text { Rockwell } \\
\text { hardness } \\
(\mathrm{HRC})\end{array}$ \\
\hline $\begin{array}{l}\text { Epoxy/kenaf/PET } \\
(60 / 20 / 20)\end{array}$ & 228.78 & 9.74 & 3.96 & 4.45 \\
\hline
\end{tabular}

shear stress distribution occurred midway between the loading nose and the cylindrical supports on both sides of the beam, leading to a high stress concentration at the loading nose and the support points. The stress concentration resulted in crack initiation in the midplane of the beam and propagates along its span before fracture. A closer observation of the specimens revealed that failure due to tension and compression on both sides of the beam can be spotted, with more damage on the tension side. In addition, a V-shaped fracture in the midplane of the specimen was observed from the tension side of the beam using an optical microscope with a magnification of 20x. It can be said that the damage zone, after failure, is characterized by fibre breakage, matrix cracking, and fibre pullout as depicted in Figure 18. Similar findings were reported by da Silva et al. [30] and Godara et al. [31].

3.5. Hardness. Hardness of the hybrid composite is its resistance to indentation or penetration, and it is also an indication of the composites ability to resist crack initiation and propagation when subjected to a sudden impact load. The results of Rockwell hardness test conducted at room temperature $\left(24^{\circ} \mathrm{C}\right)$ are summarized in Table 1 . The results revealed that the hardness number of the $60 / 20 / 20$ composition yielded much higher hardness by nearly $28 \%$ from 43 to 31 in relation to the 70/15/15 composition. The enhancement in hardness may be attributed to increase in stiffness of the composite when compared to the $70 / 15 / 15$ composition. In addition, the increase in stiffness may probably be due to stronger interfacial bonding between the fibres and the matrix, interlocking structure of the woven fabric, and increase in fibre loading as reported by other researchers $[32,33]$. Another possible explanation may be due to surface crystallization of the composite by the incorporation of PET fibre in the interwoven hybrid fabric.

3.6. Moisture Absorption, Water Absorption, Void Content, and Density. The results of moisture absorption, water absorption, and void content are presented in Figure 19. It can be seen that the moisture and water absorption of the composites decreases with increase in fibre contents. This drop in moisture content may be attributed to the occurrence of voids and microcracks in the 70/15/15 composition. A closer look at the 70/15/15 samples revealed that the surfaces of the composites are more prone to moisture absorption due to porosity and roughness on some parts of the specimens. However, there is a substantial increase in water absorption in the hybrid composites with respect to neat epoxy as depicted in Figure 19. This is expected due to the hydrophilic nature of

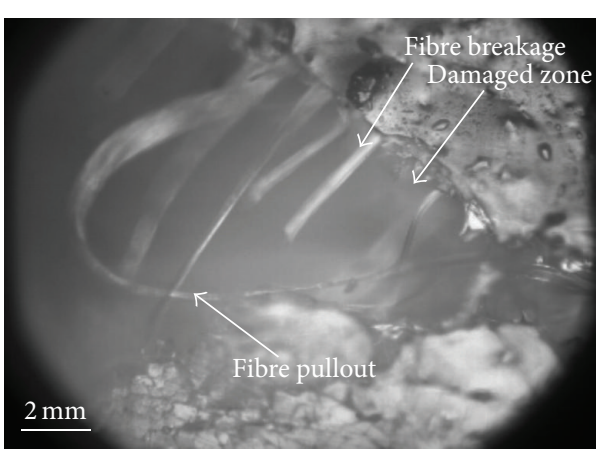

FIGURE 18: The deformed surface of the interwoven hybrid composite shows fibre pullout after the interlaminar shear test.

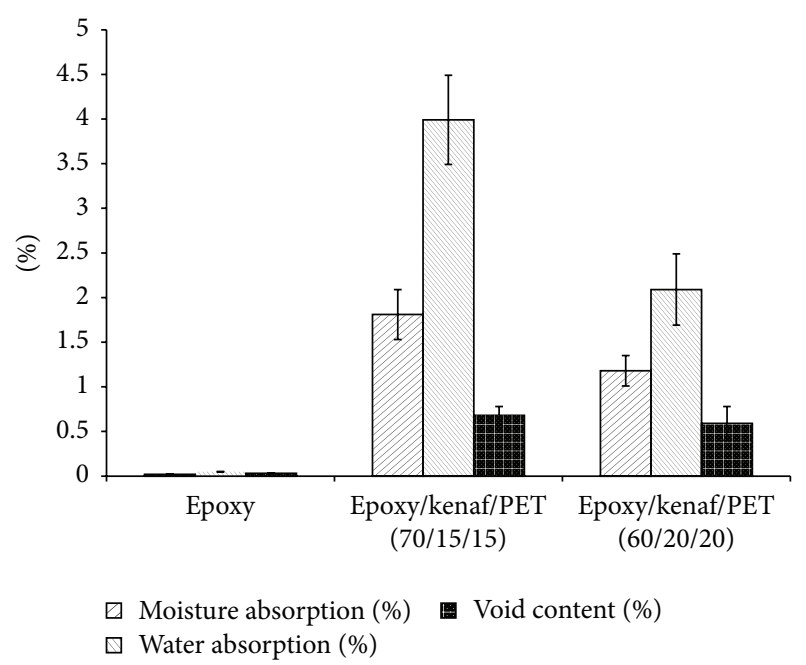

FIGURE 19: The results of moisture absorption test, water absorption, and void content.

kenaf fibre in the composites. Another possible explanation is that the kenaf fibre consists of lignin, cellulose, and hemicellulose, and the cellulose is a hydrophilic polymer consisting of hydroxyl groups. The hydroxyl group reacts with hydrogen bond of water molecules, resulting in high moisture uptake in the composite $[34,35]$. The PET fibre contribution in reducing the composite moisture uptake is insignificant due to its hydrophobic characteristics and surface crystallinity when compared to kenaf fibre.

The diffusion properties of the composites as defined by Fick's law were evaluated by weight gain measurements of predried specimens submerged in distilled water for 120 
TABLE 2: Diffusion properties and densities of the hybrid composites.

\begin{tabular}{lcccc}
\hline Samples & $\begin{array}{c}\text { Measured density } \\
\left(\mathrm{g} / \mathrm{cm}^{3}\right)\end{array}$ & $\begin{array}{c}\text { Theoretical density } \\
\left(\mathrm{g} / \mathrm{cm}^{3}\right)\end{array}$ & $\begin{array}{c}\text { Water absorption at equilibrium } \\
(\%)\end{array}$ & $\begin{array}{c}\text { Diffusion coefficient, } \\
D \times 10^{-6}\left(\mathrm{~mm}^{2} / \mathrm{s}\right)\end{array}$ \\
\hline Epoxy & 1.089 & 1.100 & 0.012 & 1.100 \\
\hline $\begin{array}{l}\text { Epoxy/kenaf/PET } \\
(70 / 15 / 15)\end{array}$ & 1.170 & 1.174 & 3.988 & 1.500 \\
\hline $\begin{array}{l}\text { Epoxy/kenaf/PET } \\
(60 / 20 / 20)\end{array}$ & 1.194 & 1.201 & 2.089 & 6.000 \\
\hline
\end{tabular}

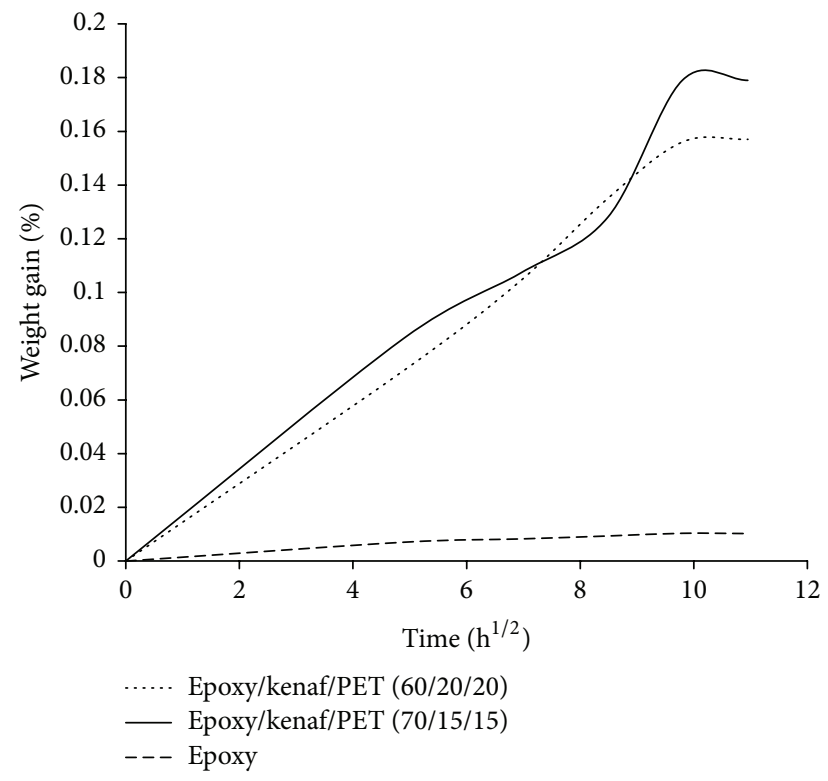

FIGURE 20: The water absorption behaviour of the interwoven hybrid composites.

hours. The diffusion coefficient $(D)$ was computed by plotting the percentage weight gain versus the square root of time and considering the slope of the curve presented in Figure 20. It was observed that, during the long time exposure, the percentage water absorption of all the specimens was high in the early stages and eventually slows down and reached saturation level, following the Fickian diffusion process as illustrated in Figure 20. In the early stage of exposure, water penetrates the composite through capillaries causing the fibres to swell and created more voids that lead to microcracking of the brittle thermosetting matrix. The presence of microcracks in the hybrid composite created larger surface area at the interface between the fibres and the matrix, which resulted in an increase in water diffusion in the composite as reported by other researchers $[36,37]$. The results of diffusion coefficients of the composites are presented in Table 2. It can be observed that the diffusion coefficient increases with an increase in fibre loading and thickness of the specimens as reported by another author [38].

The void content of the 70/15/15 composition has increased by approximately $86 \%$ from 0.03 to $0.22 \%$ in relation to neat epoxy. However, the percentage voids content of the $60 / 20 / 20$ composition dropped by nearly $13 \%$ from 0.68 to $0.59 \%$ with respect to the $70 / 15 / 15$ composition. A possible explanation is that the drop in void content may be attributed to decrease in porosity, strong interfacial bond, and decrease in surface roughness observed in the 60/20/20 composition. Some researchers have also concluded that the increase in void content has a detrimental effect on transverse stress and fibre-matrix interfacial adhesion [36, 37]. It can be said that the more the void content and microcracks in the composites, the higher the capillarity and moisture uptake along the fibrematrix interface. The theoretical and experimental densities of the composites are also presented in Table 2, and the results show a marginal increase in measured density of the hybrid composites compared to neat epoxy. A similar trend was observed in the theoretical density of the 70/15/15 composition, where a marginal increase of approximately $6 \%$ was observed compared to neat epoxy. Therefore, It can be said that the densities of the individual reinforcements and the matrix accounted for the slight increase in the composite density.

\section{Conclusion}

The mechanical and physical properties of the interwoven hybrid composite have been studied and analysed with respect to neat epoxy. The production method adopted was vacuum infusion due to its advantages over hand lay-up technique, such as high fibre volume fraction, low void content, and strong interfacial bonding. A substantial increase in tensile strength and elastic modulus of approximately $73 \%$ and $58 \%$ was realized in the $60 / 20 / 20$ composition, respectively. This enhancement in tensile strength and elastic modulus may be attributed to the contributions of individual properties of kenaf and PET fibres and strong interfacial bonding between the fibres and the thermosetting matrix. Similarly, a significant increase in flexural and impact properties was also recorded, and this improvement may be attributed to the ability of individual reinforcement to withstand bending forces and impact energy. The water absorption pattern of the composite was found to follow Fickian behaviour at room temperature. The increase in voids and microcracks in the composites accounted for an increase in moisture uptake along the fibre-matrix interphase, during the long time exposure in distilled water.

\section{Conflict of Interests}

The authors declare that there is no conflict of interests regarding the publication of this paper. 


\section{References}

[1] S. Dai, P. R. Cunningham, S. Marshall, and C. Silva, "Influence of fibre architecture on the tensile, compressive and flexural behaviour of 3D woven composites," Composites Part A: Applied Science and Manufacturing, vol. 69, pp. 195-207, 2015.

[2] A. Porras and A. Maranon, "Development and characterization of a laminate composite material from polylactic acid (PLA) and woven bamboo fabric," Composites Part B: Engineering, vol. 43, no. 7, pp. 2782-2788, 2012.

[3] R. Yahaya, S. M. Sapuan, M. Jawaid, Z. Leman, and E. S. Zainudin, "Mechanical performance of woven kenaf-Kevlar hybrid composites," Journal of Reinforced Plastics and Composites, vol. 33, no. 24, pp. 2242-2254, 2014.

[4] Y. Dan-mallam, M. Z. Abdullah, and P. S. M. Megat Yusoff, "The effect of hybridization on mechanical properties of woven kenaf fiber reinforced polyoxymethylene composite," Polymer Composites, vol. 35, no. 10, pp. 1900-1910, 2014.

[5] Y. Mahadik, K. A. R. Brown, and S. R. Hallett, "Characterisation of $3 \mathrm{D}$ woven composite internal architecture and effect of compaction," Composites Part A: Applied Science and Manufacturing, vol. 41, no. 7, pp. 872-880, 2010.

[6] W.-S. Kuo, T.-H. Ko, and C.-P. Chen, "Effect of weaving processes on compressive behavior of 3D woven composites," Composites Part A: Applied Science and Manufacturing, vol. 38, no. 2, pp. 555-565, 2007.

[7] A. P. Mouritz and B. N. Cox, "A mechanistic interpretation of the comparative in-plane mechanical properties of $3 \mathrm{D}$ woven, stiched and pinned composites," Composites A: Applied Science and Manufacturing, vol. 41, no. 6, pp. 709-728, 2010.

[8] S. D. Pandita and I. Verpoest, "Prediction of the tensile stiffness of weft knitted fabric composites based on X-ray tomography images," Composites Science and Technology, vol. 63, no. 2, pp. 311-325, 2003.

[9] T. J. Whitney and T. Chou, "Modelling of 3-D angle-interlock textile structural composites," Journal of Composite Materials, vol. 23, no. 9, pp. 890-911, 1989.

[10] D. Modi, M. Johnson, A. Long, and C. Rudd, "Analysis of pressure profile and flow progression in the vacuum infusion process," Composites Science and Technology, vol. 69, no. 9, pp. 1458-1464, 2009.

[11] Y. Dan-mallam, M. Z. Abdullah, and P. S. Megat Yusoff, "Impact strength, microstructure, and water absorption properties of kenaf/polyethylene terephthalate (PET) fiber-reinforced polyoxymethylene (POM) hybrid composites," Journal of Matererials Research, vol. 28, no. 16, pp. 2142-2146, 2013.

[12] J.-K. Kim, C. Hu, R. S. C. Woo, and M.-L. Sham, "Moisture barrier characteristics of organoclay-epoxy nanocomposites," Composites Science and Technology, vol. 65, no. 5, pp. 805-813, 2005.

[13] T. Alomayri, H. Assaedi, F. U. A. Shaikh, and I. M. Low, "Effect of water absorption on the mechanical properties of cotton fabricreinforced geopolymer composites," Journal of Asian Ceramic Society, vol. 2, pp. 223-230, 2014.

[14] Y. A. El-Shekiel, M. S. Sapuan, K. Abdan, and E. S. Zainudin, "Development of a new kenaf Bast fibre reinforced thermoplastic polyurethane composite," BioResources, vol. 6, no. 4, pp. 4662-4672, 2011.

[15] C. Girisha, Sanjeevarmuthy, R. Gunti, and S. Manu, "Mechanical performance of natural fibre reinforced epoxy hybrid composites," International Journal of Engineering Research and Application, vol. 2, no. 5, pp. 615-619, 2012.
[16] K. H. Leong, B. Lee, I. Herszberg, and M. K. Bannister, "Effect of binder path on the tensile properties and failure of multilayer woven CFRP composites," Composites Science and Technology, vol. 60, no. 1, pp. 149-156, 2000.

[17] F. Stig and S. Hallström, "Assessment of the mechanical properties of a new 3D woven fibre composite material," Composites Science and Technology, vol. 69, no. 11-12, pp. 1686-1692, 2009.

[18] M. R. Garnich and G. Karami, "Finite element micromechanics for stiffness and strength of wavy fiber composites," Journal of Composite Materials, vol. 38, no. 4, pp. 273-292, 2004.

[19] A. E. Bogdanovich, M. Karahan, S. V. Lomov, and I. Verpoest, "Quasi-static tensile behaviour and damage of carbon/epoxy composite reinforced with 3D non-crimp orthogonal woven fabric," Mechanics of Materials, vol. 62, pp. 14-31, 2013.

[20] L. Tong, P. Tan, and G. P. Steven, "Effect of yarn weaviness on strength of 3D orthogonal woven CFRP composite materials," Journal of Reinforced Plastics and Composites, vol. 21, no. 2, pp. 153-173, 2002.

[21] M. Jawaid, H. P. S. A. Khalil, A. A. Bakar, A. Hassan, and R. Dungani, "Effect of jute fibre loading on the mechanical and thermal properties of oil palm-epoxy composites," Journal of Composite Materials, vol. 47, no. 13, pp. 1633-1641, 2013.

[22] R. Ghosh, A. R. Krisha, G. Reena, and B. L. Raju, "Effect of fiber volume fraction on the tensile strength of banana fiber reinforced vinylester resin composites," International Journal of Advanced Engineering Science and Technology, vol. 4, no. 1, pp. 89-91, 2011.

[23] M. Jawaid, H. P. S. Abdul Khalil, and A. Abu Bakar, "Woven hybrid composites: tensile and flexural properties of oil palmwoven jute fibres based epoxy composites," Materials Science and Engineering: A, vol. 528, no. 15, pp. 5190-5195, 2011.

[24] Y. Wang and D. Zhao, "Effect of fabric structures on the mechanical properties of 3D textile composites," Journal of Industrial Textiles, vol. 35, no. 3, pp. 239-256, 2006.

[25] E. Soliman, U. Kandil, and M. R. Taha, "Improved strength and toughness of carbon woven fabric composites with functionalized MWCNTs," Materials, vol. 7, no. 6, pp. 4640-4657, 2014.

[26] S. Y. Fu, B. Lauke, E. Mäder, X. Hu, and C. Y. Yue, "Fracture resistance of short-glass-fiber-reinforced and short-carbonfiber-reinforced polypropylene under Charpy impact load and its dependence on processing," Journal of Materials Processing Technology, vol. 89-90, pp. 501-507, 1999.

[27] S. Rahmanian, A. R. Suraya, M. A. Shazed, R. Zahari, and E. S. Zainudin, "Mechanical characterisation of epoxy composite with multiscale reinforcements: carbon nanotubes and short carbon fibres," Materials Design, vol. 60, pp. 34-40, 2014.

[28] M. Tehrani, A. Y. Boroujeni, T. B. Hartman, T. P. Haugh, S. W. Case, and M. S. Al-Haik, "Mechanical characterization and impact damage assessment of a woven carbon fiber reinforced carbon nanotube-epoxy composite," Composites Science and Technology, vol. 75, pp. 42-48, 2013.

[29] M. S. Madhukar and L. T. Drzal, "Fiber-matrix adhesion and its effect on composite mechanical-properties. In lane and interlaminar shear behaviour of graphite epoxy composites," Journal of Composite Material, vol. 25, no. 8, pp. 9320-9957, 1999.

[30] L. V. da Silva, J. H. S. A. Júnior, C. C. Angrizani, and S. C. Amico, "Short beam strength of curaua, sisal, glass and hybrid composites," Journal of Reinforced Plastics and Composites, vol. 32, no. 3, pp. 197-206, 2012.

[31] A. Godara, L. Gorbatikh, G. Kalinka et al., "Interfacial shear strength of a glass fibre/epoxy bonding in composites modified 
with carbon nanotubes," Composite Science and Technology, vol. 70, pp. 1346-1352, 2010.

[32] M. M. Haque, M. Hasan, M. S. Islam, and M. E. Ali, "Physicomechanical properties of chemically treated palm and coir fiber reinforced polypropylene composites," Bioresource Technology, vol. 100, no. 20, pp. 4903-4906, 2009.

[33] M. R. Rahman, M. M. Huque, M. N. Islam, and M. Hasan, "Improvement of physico-mechanical properties of jute fiber reinforced polypropylene composites by post-treatment," Composites Part A: Applied Science and Manufacturing, vol. 39, no. 11, pp. 1739-1747, 2008.

[34] H. N. Dhakal, Z. Y. Zhang, and M. O. W. Richardson, "Effect of water absorption on the mechanical properties of hemp fibre reinforced unsaturated polyester composites," Composites Science and Technology, vol. 67, no. 7-8, pp. 1674-1683, 2007.

[35] A. Bismarck, I. Aranberri-Askargorta, J. Springer et al., "Surface characterization of flax, hemp and cellulose fibers; surface properties and the water uptake behavior," Polymer Composites, vol. 23, no. 5, pp. 872-894, 2002.

[36] A. Espert, F. Vilaplana, and S. Karlsson, "Comparison of water absorption in natural cellulosic fibres from wood and one-year crops in polypropylene composites and its influence on their mechanical properties," Composites Part A: Applied Science and Manufacturing, vol. 35, no. 11, pp. 1267-1276, 2004.

[37] A. A. A. Rashdi, S. M. Sapuan, M. M. H. M. Ahmad, and A. Khalina, "Water absorption and tensile properties of soil buried kenaf fibre reinforced unsaturated polyester composites (KFRUPC)," Journal of Food, Agriculture and Environment, vol. 7, no. 3-4, pp. 908-911, 2009.

[38] W. Wang, M. Sain, and P. A. Cooper, "Study in moisture absorption of natural fibre composites," Composite Science and Technology, vol. 66, pp. 379-386, 2006. 

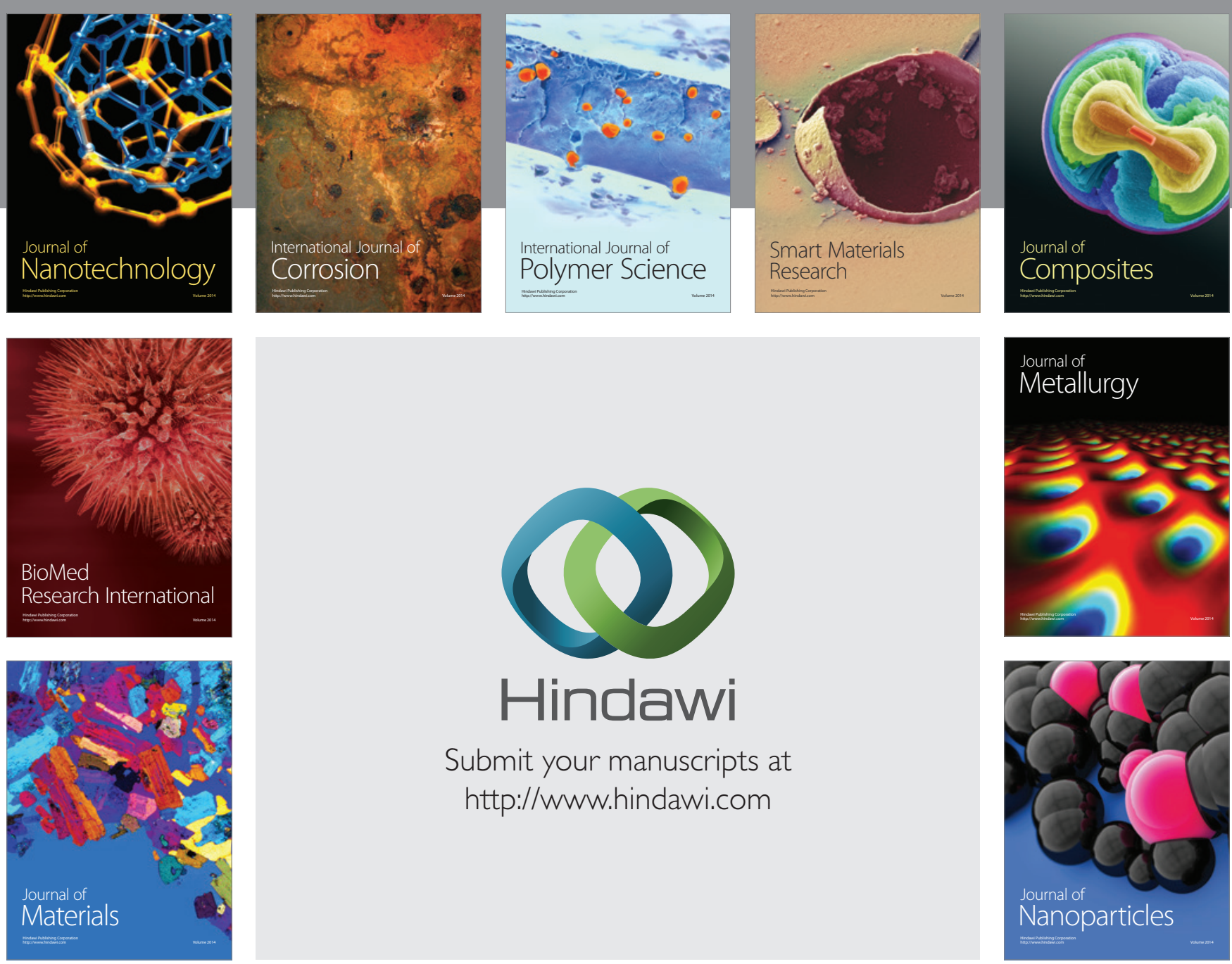

Submit your manuscripts at http://www.hindawi.com
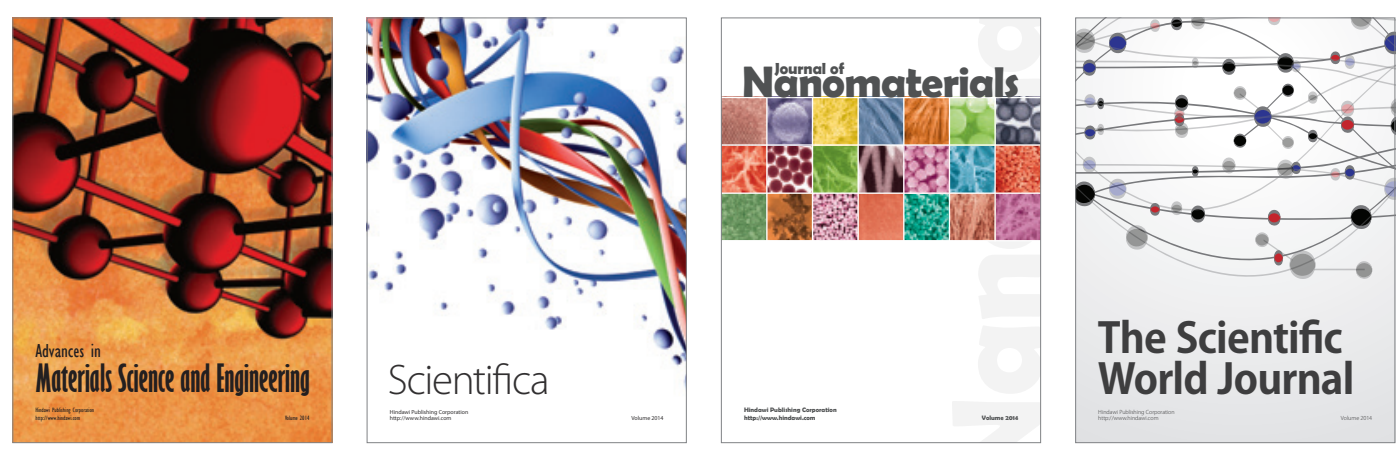

\section{The Scientific World Journal}
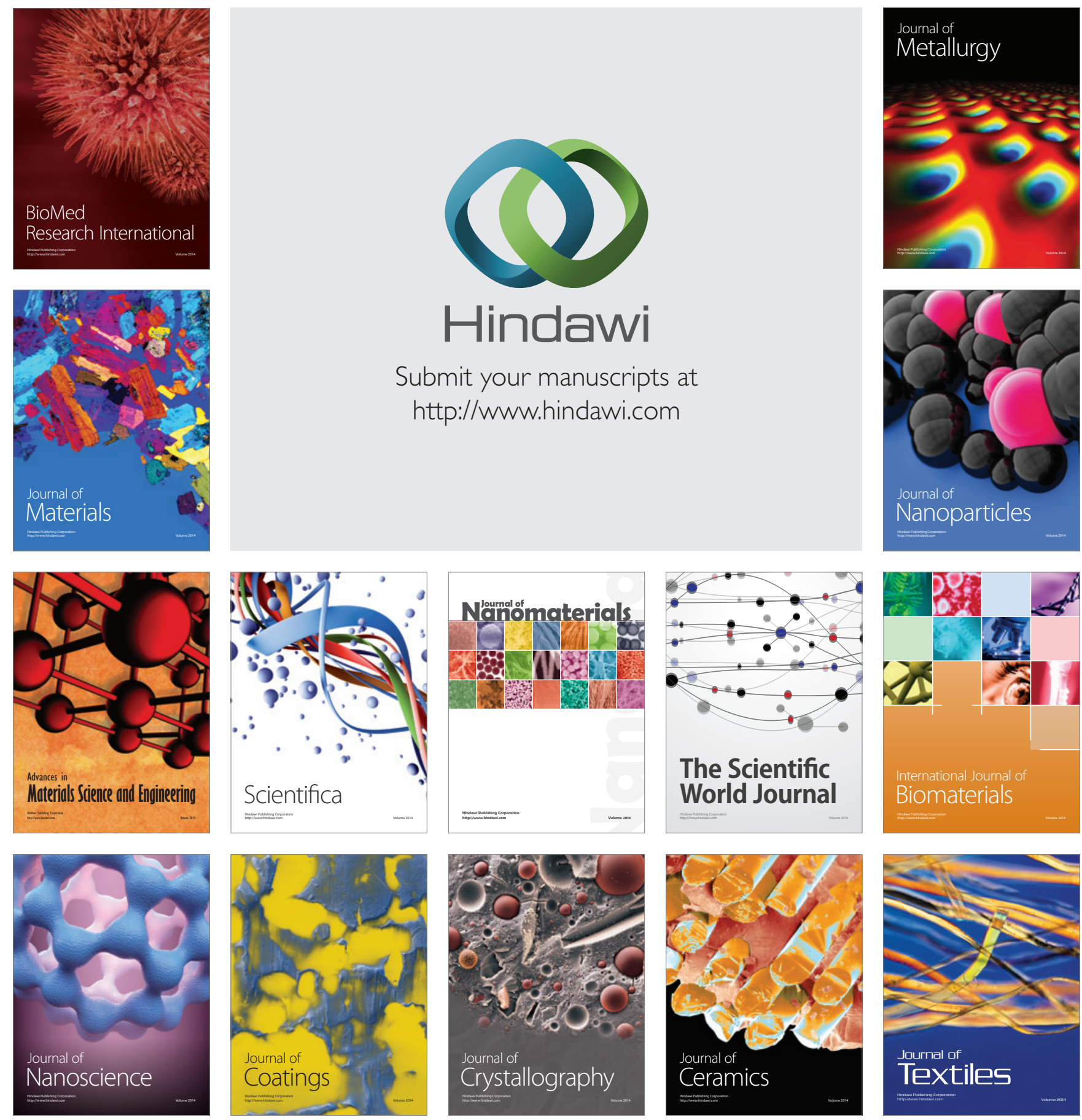